(3)

Volume 21, 2018

\title{
Transdisciplinary KnOWledge Producing Teams: TOWARd A COMPLEX Systems PERSPECTIVE
}

Gaetano R. Lotrecchiano*

Shalini Misra

* Corresponding author
George Washington University, Washington, DC, USA

Virginia Tech, Alexandria, VA, USA
Glotrecc@gwu.edu

Shalini@,vt.edu

\section{ABstract}

Aim/Purpose

Background

Methodology

Contribution

Findings

Recommendations for Practitioners

Recommendation for Researchers
Transdisciplinarity is considered as a framework for understanding knowledge producing teams (KPTs). Features of transdisciplinary knowledge producing teams (TDKPTs) are provided using a complex adaptive systems (CAS) lens. TDKPT features are defined and linked to complexity theory to show how team participants might develop skills that more truly express complex adaptive conditions.

TDKPTs are groups of stakeholder participants tasked with producing knowledge across disciplinary, sectoral, and ecological boundaries. TDKP'Ts reflect components of complex adaptive systems (CAS) and exemplify how CAS behave and function.

The paper accesses literature from the Science-of-Team-Science (SciTS), complexity theory, and systems theory to construct a typology of the features of TDKPTs.

This paper provides a list of features developed from a diverse body of literature useful for considering complexity within TDKPTs.

The paper proposes a series of features of transdisciplinary knowledge producing teams. In addition, the authors identify important skill building aspects needed for TDKPTs to be successful.

The paper provides a framework by which team functioning can be considered and enhanced within TDKPTs.

The paper suggests categorical features of transdisciplinary teams for research on the collaborative processes and outcomes of TD teams.

This paper is one in a Special Series on Transdisciplinary Communication

Accepting Editor Eli Cohen | Received: May 24, 2018 | Revised: June 19, 2018 | Accepted: June 30, 2018. Cite as: Lotrecchiano, G. R., \& Misra, S. (2018). Transdisciplinary knowledge producing teams: Toward a complex systems perspective. Informing Science: the International Journal of an Emerging Transdiscipline, 21, 51-74. https://doi.org/10.28945/4086

(CC BY-NC 4.0) This article is licensed to you under a Creative Commons Attribution-NonCommercial 4.0 International License. When you copy and redistribute this paper in full or in part, you need to provide proper attribution to it to ensure that others can later locate this work (and to ensure that others do not accuse you of plagiarism). You may (and we encourage you to) adapt, remix, transform, and build upon the material for any non-commercial purposes. This license does not permit you to use this material for commercial purposes. 
Features of TDKPTs

Impact on Society The features of TDKPTs developed and described in this paper inform the development of the requisite skill set for better team functioning. This offering attracts researchers of TD teams and TD team members alike to reconsider the development and study of TDKPTs.

Future Research Knowledge producing team members need to engage in theoretical, epistemological, and methodological reflections to elucidate the dynamic nature of TD knowledge producing teams. Understanding how conflict, dissonance, and reciprocal interdependencies contribute to knowledge generation are key areas of future research and inquiry.

Keywords transdisciplinarity, knowledge producing teams, complexity, systems

\section{INTRODUCTION}

Transdisciplinary (TD) teams are groups of researchers, scholars, practitioners, and community stakeholders who address problems at the intersection of scientific disciplines. They create knowledge that integrates the tools, techniques, and/or theories of disparate sectors that would not be achievable without collaboration (Somerville \& Rapport, 2002). TD teams are, by nature, knowledge-producing teams (KPTs) that strive to increase methodological diversity, engage in crossdisciplinary knowledge building, and leverage pools of intellectual resources to understand and address real-world problems (Bear \& Woolley, 2013; Jones, Wuchty, \& Uzzi, 2008; Kyvik \& Teigen, 1996; Lotrecchiano et al., 2016). "Transdisciplinary research project[s] rely on the transdisciplinary process of joint problem definition, problem-solving, and implementation that involves temporary cooperation between researchers and practitioners. Effects are intended and caused both in the scientific sphere and in practice-the societal sphere" (Walter, Helgenberger, Wiek, \& Scholz, 2007, p. 326). In order to integrate and transcend the boundaries of any single discipline, members of transdisciplinary knowledge-producing teams (TDKPTs) must understand the connections between different knowledge communities (Gray, 2008) and focus on becoming adequately versed and skilled in disciplines and fields other than their own (Borner et al., 2010; Repko \& Szostak, 2016). This type of social learning, one that allows cognitive shifts in understanding through observation of and participation with others, is a key component of successful and effective transdisciplinary teaming activity (Bandura, 1977). Collaborative learning is facilitated through the creation of shared conceptual frameworks (Park \& Son, 2010) and mental models (Cannon-Bowers, Salas, \& Converse, 1993) as teams engage in participatory approaches to generate new knowledge (Tress, Tress, \& Fry, 2003). The co-evolving social learning that is a result of these collaborations allows teams to address and attempt to solve complex problems (Schwandt, 2008).

The study of the collaborative processes and outcomes of transdisciplinary knowledge producing teams (TDKPTs) poses some unique challenges. TDKPTs cope with systemic complexities while striving to maintain focus on their scientific and pragmatic goals (Hirsch Hadorn et al., 2007). One category of systemic complexity pertains to the barriers to TD integration arising from interpersonal interactions in TD team-based contexts, called interactive systemic complexities. Interactive systemic challenges to TD integration include perceived inequitable contributions to the project (Lotrecchiano, 2012), unbalanced problem ownership, discontinuous participation, fear of failure (Lang et al., 2012), variability in communication types and skills, overall lack of participant satisfaction with the project processes and outcomes (Crowston, Specht, Hoover, Chudoba, \& Watson-Manheime, 2015), among others.

Structural systemic complexities, on the other hand, are barriers to TD integration that arise from characteristics inherent to the makeup of teams. These include differences in foundational training among team members, diverse and changing career paths, geographic dispersion, a lack of awareness of the breadth and complexity of the problem, perceived insufficient legitimacy of a team to solve the problem, conflicting methodological standards, conflicting epistemological and ontological orienta- 
tions (Lang et al., 2012), and differing levels of transdisciplinary orientation among team members (Misra, Stokols, \& Cheng, 2016).

One approach to the study of the processes and outcomes of TDKPTs is to focus on the tangible products of such teams, such as publication counts and bibliometric outcomes. The assumption is that scientific outputs are indicators of successful team processes (Hall et al., 2012). Others studies have used cognitive, structural, and developmental approaches, focusing on teams' abilities to process information, their makeup, and/or interpersonal dynamics to understand the interactive dynamics of teams and support and develop them (Gray, 2008; Mickan \& Rodger, 2005; Paletz \& Schunn, 2010; Shuffler, DiazGranados, \& Salas, 2011). Still other approaches have emphasized individual-level analyses and competency-based approaches that highlight individual skills as they enable individual team members to be more effective team members and engage in complex problem-solving (Boon, Den Hartog, Boselie, \& Paauwe, 2011; Salas, Shuffler, Thayer, Bedwell, \& Lazzarra, 2015). Research approaches that emphasize any one level of analysis, or focus solely on products or processes, are likely to fall short of capturing the dynamism and emergent changes that occur within TDKPTs (Bedwell et al., 2012; Wheatley, 1999).

In this paper, we conduct a descriptive analysis of characteristics of TDKPTs from a systems perspective (Cilliers, 1998) as an approach to the study of TDKPTs that address some of the limitations of prior approaches. We first describe how transdisciplinarity (TD), as a construct, could be used to frame an understanding of KPTs. Second, we go on to describe features of these teams using a complex systems lens and consider the types of skills members of TDKPTs might require for effective collaboration.

\section{TRANSDISCIPLINARITY AND TRANSDISCIPLINARY KNOWLEDGE PRODUCING TEAMS (TDKPTS)}

The first use of the term transdisciplinarity is credited to the Swiss psychologist Jean Piaget. In his treatise on the subject, he framed transdisciplinarity as a "higher stage of succeeding interdisciplinary relationships... which would not cover interactions or reciprocities between specialized research projects, but would place these relationships within a total system without any firm boundaries between disciplines" (Piaget, 1972, p. 138). Hence, from its inception, transdisciplinary economies of knowledge production were grounded in systems thinking that aimed to understand entire multi-level networks of individuals, organizations, and knowledge. Numerous scholars have continued to refine and expand upon the theoretical and applied properties of transdisciplinarity in an attempt to bridge this definition to applied problem-solving (Gibbons et al., 1994; Jantsch, 1972a, 1972b; Klein, 1996; Kockelmans, 1979; Rosenfield, 1992). However, the application of the term as an applied model of problem-solving is credited to the Romanian physicist, Basarab Nicolescu, who advanced the applicability of the term to contemporary problem solving by emphasizing how transdisciplinary perspectives aided in understanding the world beyond the frameworks of any one discipline (Nicolescu, 2002). A number of lines of inquiry have focused on the conceptual work of defining transdisciplinarity and have contributed to our understanding of the nature of knowledge integration - complex and adaptive systems perspectives (Cilliers, 2013); humanities discourses (Klein, 2014); socially responsible science (Hirsch Hadorn et al., 2007; Maxwell, 2005); defining and dealing with "wicked problems" (Brown, Harris, \& Russell, 2010); re-imagining disciplinary silos and boundaries (Choi \& Pak, 2007); and the multiplicity of realities in science (Nicolescu, 2002, 2012).

This conceptual research over the past two decades has permeated the research agendas of many sectors. Reference to the TD paradigm has shown up in documentation about learning, education, and science by organizations such as the United States National Science Foundation (NSF), National Institutes of Health (NIH), National Academy of Sciences (NAS), the United Nations Education, Scientific and Cultural Organization (UNESCO), and the International Center for Transdisciplinary Research (CIRET). Each has invited conversation about the tensions and complexities in interchange across knowledge systems (Cooke \& Hilton, 2015; International Center for Transdisciplinary 
Research, 2018; National Science Foundation, 2018; UNESCO, 1998). This process of engaging in "boundary crossing" (Klein, 1996), "boundary blurring" (Becher, 1990), and identifying "zones of interdependence" between boundaries is fraught with barriers and challenges. Strategies and approaches to overcome some of these barriers and manage the challenges of cross-disciplinary collaboration are critical for solving global problems. As well, addressing the differences and fundamental limitations of certain types of knowledge economies and methodologies are essential to facilitate knowledge integration. Knowledge economies by nature are focused on "production and services based on knowledge-intensive activities that contribute to an accelerated pace of technical and scientific advancement, as well as rapid obsolescence... with a greater reliance on intellectual capabilities than on physical inputs or natural resources" (Powell \& Snellman, 2004, p. 199). How this occurs is an important topic to address to facilitate complex problem-solving.

TDKPTs explicitly aim to integrate knowledge and address wicked problems. Transdisciplinary teams are distinct from unidisciplinary, interdisciplinary, and multidisciplinary teams. While each of these teams strives to produce knowledge and address a scientific problem, there are several distinctions between these economies of knowledge and the level of collaboration that occurs within each type of team. One set of differences concerns the representation of distinct disciplines, the diversity of knowledge systems, and attitudes towards other disciplinary worldviews and methodologies. Unidisciplinary teams work within the confines of the traditions or expectations of a single disciplinary history and scope. Sometimes these teams have negative biases toward other disciplines and deny the validity, rigor, and usefulness of certain disciplines, approaches, ontological assumptions, epistemics, and methods (Allan, 2007). For the purpose of comparison to other more cross-disciplinary interactive modalities, unidisciplinary teams typically adopt the oneness of a disciplinary approach with little consideration of parallel or adjacent disciplines.

Multidisciplinary teams involve individuals from two or more disciplines working together on a common problem (Graybill, Dooling, Vivek, \& John, 2006). This economy is employed in many cross-disciplinary teams throughout many sectors that require professional expertise to interface with scientific and scholarly expertise. Each participant brings to the discourse their own theories, methods, and techniques and provides insights within the confines of their own discipline. Multidisciplinary teams though extremely effective in incorporating multiple perspectives to understand or address a problem often lack the inventiveness to put forth new techniques or models, modify mainstream approaches, or construct new frameworks that integrate or transcend the confines of any one discipline. They are effective in solving problems that are less complex than those attempted by other more interactive cross-disciplinary teams. These teams often attempt to achieve greater understanding and knowledge through the multiplication of methods and not through hybridization of approaches (Klein, 1990).

Moving further along the continuum of cross-disciplinary collaboration, when teams made up of individuals from distinct disciplines modify (or synthesize) existing methods or theories stemming from the cross-pollination of two or more disciplines they are interdisciplinary in nature (Klein, 1990). However, interdisciplinary teams, though more intent on integrating knowledge are less focused on generating new knowledge that might result in new methods or frameworks that are the result of collaborative efforts. In both cases (multi- and interdisciplinary teams), a new level of discourse does emerge which ultimately leads to a further integration of knowledge (Graybill et al., 2006; Klein, 1990). Klein (1998) suggests that interdisciplinarity is a paradox, generating productive tensions that supplement, complement, and critique existing structures. This is in line with contemporary complexity thinking on adaptation in groups and organizations where tension and conflict can breed change and innovation (Burnes, 2005; Plsek \& Wilson, 2001; Wheatley, 1999). The tensions promote the expansion of individual worldviews and the creation of new frameworks to manage knowledge. Without the development of new frameworks to manage such new knowledge, exchanges cannot have a lasting impact on problems requiring new theoretical or constitutive lenses (Klein, 1996). 
Interdisciplinarity offers new ways of working in teams. New styles of thought begin to emerge and upend traditional methodologies and analytical enterprises to generate new frames of knowledge (Pirrie, Wilson, \& Elsewood, 1998). This sentiment echoes that of earlier theorists, who also focused on the shifts that occur between disciplinary boundaries resulting in novel perspectives and paradigm shifts, but highlighted different mechanisms like scientific paradigm shifts, differentiation and integration of scientific knowledge, and interdependences (Kuhn, 1970; Lawrence \& Lorsch, 1967; Thompson, 1967).

Multi- and interdisciplinary team approaches both fall short of knowledge integration in a manner unique to TDKPTs. Transdisciplinarity is a departure from mere considerations of hybridization and synthesis of disciplinary perspectives, methods, or frameworks. While multidisciplinary and interdisciplinary teams focus on exchanges between disciplines, TDKPTs teams operate from a fundamentally different paradigm that endeavors to work across disciplines and non-disciplinary knowledge systems with the goal of engaging in participatory knowledge-creation across epistemic and methodological boundaries (Dillon, 2008; Huutoniemi, Klein, Bruun, \& Hukkinen, 2010). Maasen and Lieven (2006) describe transdisciplinarity as a new mode of governing science where “...practices are directed toward solving complex policy issues and address scientific knowledge production proper. It promises to circumvent the schism between scientific expertise and policy-making by... the involvement of stakeholders [that] make sure the 'right problem' gets addressed 'in the right way"'(Maasen \& Lieven, 2006, p. 400). Transdisciplinarity, therefore, moves us from a consideration of science as bound by disciplines and gravitates to a more holistic and systemic schema that considers the dynamics of entire systems of actors and concepts (Hammond \& Dubé, 2012; Klein, 1990; Lotrecchiano, 2010; Tress et al., 2003). Maasen and Lieven (2006) characterize TDKPTs as "extending expertise," and "legitimation through participation" rather than "legitimation through knowledge."

In TDKPTs participants are challenged to relate to and reconcile with different levels of reality (Wickson, Carew, \& Russell, 2006) thus challenging the very core of their beliefs and assumptions about knowledge. Furthermore, the transfer of power, reinterpretations of service delivery, training and education requirements, and questions of legitimacy all contribute to a general resistance to transdisciplinarity (Fine, 2007). These tensions become real as traditional roles and disciplines are challenged to change and evolve in TD collaborations. TD team interactions are subject to unfavorable conditions that make it difficult to transition from an interdisciplinary mode to this more novel and integrative one. TDKPTs, therefore, require a reappraisal and a reconsideration of the systemic features and properties if integration and synthesis are to truly occur. Figure 1 provides a graphical representation of the distinctions between uni-, multi-, inter-, and transdisciplinarity. We now turn our focus to a systems analysis of the features of TDKPTs.

Figure 1 depicts the differing levels of interdependency for the various types of cross-disciplinary collaboration. There is no interdependency between different disciplines in unidisciplinary knowledge producing teams. In multidisciplinary teams, multiple closed systems $(O)$ participate in problemsolving within one larger organization through overlapping interests, but with little or no integration. Multidisciplinarity, therefore, is driven by standardization and a general investment into the entire system through the unidisciplinary representation of one's own profession or disciplinary perspective. In interdisciplinary economies of knowledge, integration occurs as different disciplines interact and integrate perspectives, theories, or methods $\square$ ). Transdisciplinary knowledge producing teams are driven by goals that include integrated input/output $(\square)$, but also transform and transcend disciplines by different types of reorientation (e.g., the creation of new conceptual frameworks that go beyond the knowledge of any single discipline) $\square$, $\Delta$, etc.) 
UNIDISCIPLINARITY

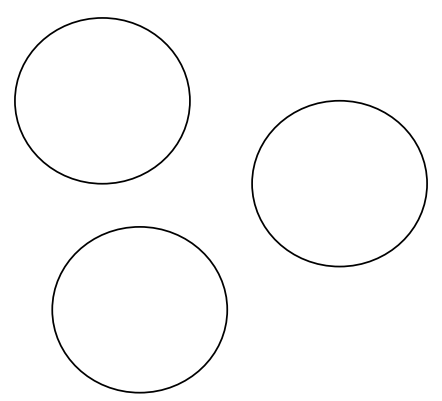

- Singularized histories, traditions, and expectations

- Linear perspective

- Closed systems

- Common knowledge within disciplines

- Non-interactive, no interdependence

- Codified reality

\section{INTERDISCIPLINARITY}

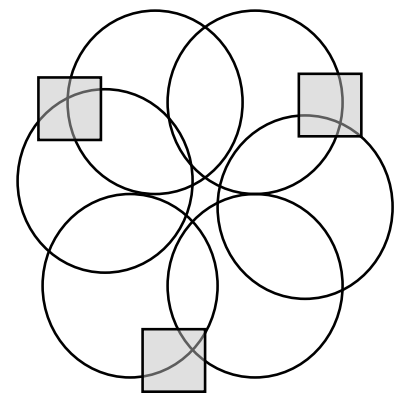

- Intersecting histories, traditions, and expectations

- Intersecting perspectives

- Interactive system

- Adjusted knowledge across disciplines

- Blended interaction, Sequential interdependence

- Common reality
MULTIDISCIPLINARITY

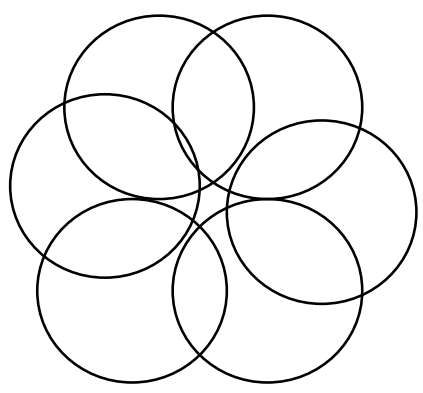

- Shared histories, traditions, and expectations

- Poly-linear perspectives

- Permeable system

- Shared knowledge across disciplines

- Dialogic interaction, pooled interdependence

- Similar reality

\section{TRANSDISCIPLINARITY}

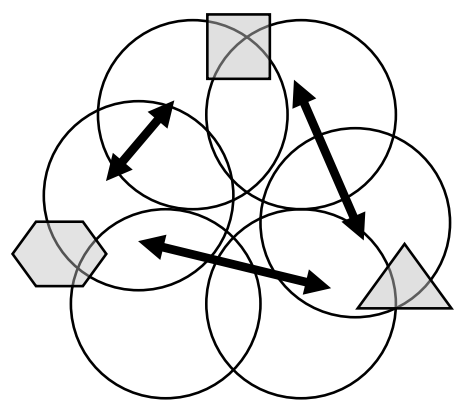

- Holistic histories, traditions, and expectations

- Amalgamated perspective

- Open system

- Generating knowledge across disciplines

- Reciprocal interdependence

- Multiple realities

- Transformative

Figure 1. Complexity Perspectives of Cross-Disciplinary Knowledge Economies (adapted from Lotrecchiano, 2011). 


\section{Features of Transdisciplinary Knowledge Producing TEAMS (TDKPTS)}

To describe the overlapping themes in transdisciplinary knowledge economies and TDKPTs we look to complexity science to understand how one might strive toward defining and developing the skills necessary to work within these teams. In the sections below, we introduce a typology of TD features under two categories—structural system complexities and interactive system complexities—and elucidate the complexity factors they parallel and skills required to work within these environments. Underlying these features are several key assumptions about TDKPTs that are important to consider as we articulate the shared elements of TDKPTs with complex adaptive systems. We additionally offer definitions associated with Complex Adaptive Systems (CAS) as they are key to the descriptions that follow.

\section{Assumptions about TDKPTs}

TDKPTs operate within evolving environmental conditions as they strive to create new frameworks for managing novel knowledge outputs (N. Morgan, 2002). This evolving environment is recognizable through the dynamic interactions of teams (Stokols et al., 2003).

TDKP'Ts by nature express adaptive qualities (those required for change) that are often manifested during moments of conflict and tension that are byproducts of evolution and change (HagemeierKlose, Beichler, Davidse, \& Deppisch, 2004). These conflicts are moments of knowledge awareness and exchange and not necessarily barriers to teaming (Blau, 1964; Buckley, 1998).

TDKPT mechanisms are not bound to any one feature. There is an enormous amount of overlap between different TDPKT features. To consider otherwise would be contrary to the systems approach being adopted here.

TDKPT features are found on the individual, group and organizational levels of any system affecting individuals and teams as they interface with their environment (Borner et al., 2010). Any description of features needs to be cognizant of the individual, team, and environmental factors that contribute to any knowledge economy.

TDKPTs are complex and adaptive environments (complex adaptive systems) that utilize techniques for communication and exchange that ascribe to principles found in systems theory like adaptation, nonlinearity, openness, and self-organization (Cilliers, 2013).

\section{A Complex Adaptive Systems (CAS) Primer}

Information exchange occurs through the interactions of multiple elements.

Non-linearity in CAS is the result of a lack of any one dominant framework bounding the flow of information.

CAS are open systems with feedback loops, both enhancing, stimulating (positive) or detracting, inhibiting (negative). Both kinds are necessary.

CAS are open systems where feedback loops serve as entropy in the system stimulating and inhibiting flow at any given time.

Change is a continual steady state in CAS where equilibrium is equated with the death of the system.

The depth and history of a complex adaptive system is common knowledge but not depicted

through any one entity, event, or actor in the system. All activities contribute to the growing

knowledge about the system.

Interactions between systems components is a foundational feature of CAS.

(Adapted from Cilliers, 1998) 
Having delineated the basic assumptions for a systems' understanding of the features of TDKPTs, we present key features of TDKPTs along with an illustrative case that highlights the most salient or primary systems principles invoked in the feature. Table 1 summarizes this information.

Table 1. Features of TD Knowledge Producing Teams

Categorized by Type of System Complexity

\section{Structural System Complexities}

Challenges:

- Perceived inequitable contributions to the project (Lotrecchiano, 2012).

- Unbalanced problem ownership, discontinuous participation, fear of failure (Lang et al., 2012).

- Variability in communication types and skills, overall lack of participant satisfaction with the project processes and outcomes (Crowston et al., 2015)

\begin{tabular}{|c|c|c|}
\hline Feature & Complexity Factor & Skill Development Foci \\
\hline $\begin{array}{l}\text { Complex prob- } \\
\text { lem solving }\end{array}$ & $\begin{array}{l}\text { Information exchange oc- } \\
\text { curs through the interac- } \\
\text { tions of multiple elements. }\end{array}$ & $\begin{array}{l}\text { A heightened focus on anticipated future } \\
\text { states (Hirsch Hadorn et al., 2007; } \\
\text { Weisbord, 2004) } \\
\text { - Goal alignment with conditions of a } \\
\text { changing world (Entin \& Serfaty, 1999) } \\
\text { - Focus on dealing with interpersonal team } \\
\text { challenges } \\
\text { - Co-developed shared mental models with- } \\
\text { in KPTs (Cannon-Bowers et al., 1993) } \\
\text { - Social learning as part of team engage- } \\
\text { ment (Schwandt, 2008) }\end{array}$ \\
\hline $\begin{array}{l}\text { Stakeholder in- } \\
\text { volvement }\end{array}$ & $\begin{array}{l}\text { CAS are open systems with } \\
\text { feedback loops, both en- } \\
\text { hancing, stimulating (posi- } \\
\text { tive) or detracting, inhibit- } \\
\text { ing (negative). Both kinds } \\
\text { are necessary }\end{array}$ & $\begin{array}{l}\text { Translation of knowledge across disci- } \\
\text { plines (Colditz, Wolin, \& Gehlert, 2012) } \\
\text { Development and sustainability of scien- } \\
\text { tific and non-scientific partnerships } \\
\text { (Maasen \& Lieven, 2006) } \\
\text { Establishing interdependence between } \\
\text { knowledge partners (Lawrence \& Lorsch, } \\
\text { 1967) }\end{array}$ \\
\hline $\begin{array}{l}\text { Methodological } \\
\text { pluralism }\end{array}$ & $\begin{array}{l}\text { Change is a continual steady } \\
\text { state in CAS where equilib- } \\
\text { rium is equated with the } \\
\text { death of the system }\end{array}$ & $\begin{array}{l}\text { - Boundary spanning over boundary form- } \\
\text { ing (Klein, 2004) } \\
\text { - Shifting awareness of problems } \\
\text { (Nicolescu, 2005b) } \\
\text { - Pluralism as a normative reality (Lamont \& } \\
\text { - Swidler, 2014) } \\
\text { - Translation of knowledge (Larson et al., } \\
\text { 2011) }\end{array}$ \\
\hline
\end{tabular}




\begin{tabular}{|c|c|c|}
\hline Praxis & $\begin{array}{l}\text { Interactions between sys- } \\
\text { tems components is a } \\
\text { foundational feature of } \\
\text { CAS }\end{array}$ & $\begin{array}{l}\text { Experience-based learning is necessary for } \\
\text { impact-based solutions (Kolb, 1984) } \\
\text { - Combining formal and informal } \\
\text { knowledge (Horlick-Jones \& Sime, 2004) } \\
\text { - Reintegrating co-created knowledge (Lang } \\
\text { et al., 2012) }\end{array}$ \\
\hline \multicolumn{3}{|l|}{ Challenges } \\
\hline Feature & Complexity Factor & Skill Development Foci \\
\hline $\begin{array}{l}\text { Open systems } \\
\text { capacity }\end{array}$ & $\begin{array}{l}\text { Non-linearity in CAS is the } \\
\text { result of a lack of any one } \\
\text { dominant framework } \\
\text { bounding the flow of in- } \\
\text { formation }\end{array}$ & $\begin{array}{l}\text { Reception to knowledge from outside of } \\
\text { one's system of knowledge (Tress et al., } \\
\text { 2003) } \\
\text { Conflict and power struggles can breed } \\
\text { innovative thought (Eldridge \& Crombie, } \\
\text { 1975) } \\
\text { Interdependent relationships between ac- } \\
\text { tors need to contribute to shared goals } \\
\text { (Katz \& Kahn, 1966) }\end{array}$ \\
\hline $\begin{array}{l}\text { Different (shift- } \\
\text { ing) levels of } \\
\text { reality }\end{array}$ & $\begin{array}{l}\text { CAS are open systems } \\
\text { where feedback loops serve } \\
\text { as entropy in the system } \\
\text { stimulating and inhibiting } \\
\text { flow at any given time }\end{array}$ & $\begin{array}{l}\text { - Navigation of multiple realities related to a } \\
\text { single problem (McGregor, 2011; Nicoles- } \\
\text { cu, 2006) } \\
\text { - Mastering the consideration of diversity } \\
\text { over different timescales, landscapes, and } \\
\text { experiential episodes (Cilliers, 2013) } \\
\text { - Adaptation through self-organization } \\
\text { (Heylighen, 2008) }\end{array}$ \\
\hline $\begin{array}{l}\text { Collaborative } \\
\text { construction } \\
\text { and reconstruc- } \\
\text { tion }\end{array}$ & $\begin{array}{l}\text { The depth and history of a } \\
\text { complex adaptive system is } \\
\text { common }\end{array}$ & $\begin{array}{l}\text { - Openness to rearranging collaborative and } \\
\text { knowledge arrangements (Balsiger, 2004) } \\
\text { Direct contact with those affected by the } \\
\text { problem attempting to be solved (Klein, } \\
\text { 2004) }\end{array}$ \\
\hline
\end{tabular}




\section{STRUCTURAL SYSTEMIC COMPLEXITIES}

\section{COMPLEX PROBLEM SOLVING}

The complex problem-solving feature is the basis for all other features of TDKPTs. This characteristic is rooted in TDKPTs' dedication to bridging scientific inquiry and pragmatic, real-world outcomes (Brown et al., 2010). Hirsch Hadorn et al. (2007) assert that different types of knowledge are needed to address wicked problems. System knowledge relates to how things can be observed in the present state and depends on the unidisciplinary expertise of those working in a specific area of impact, the existing literature, local communities of stakeholders, etc. This form of knowledge is routine in multi- and interdisciplinarity economies and often serves as the bases for exchange among team members and stakeholders. Target knowledge emphasizes the future state of a problem. Values and priorities, policies and trends, planning documents and stakeholders all have specific roles in providing solutions to wicked problems that will contribute to a future state of the environment. As target knowledge, these artifacts directly impact solutions and become the focus of inquiry. This level of knowledge widens the investments and participation of team members and stakeholders to include information that will inform a solution. Transformational knowledge is knowledge that will aid in the transition from the present state to a future state that considers the problem in a new light or through alternative lenses. This process is specific to TD knowledge economies and emphasizes the emerging dimension of TDKPTs that yields unique methods and processes in addition to novel solutions (Hirsch Hadorn et al., 2007).

The transition between different types of knowledge and the way these contribute to the impact on real-life problems occurs through a number of interactions on multiple levels contributing to the complexity of the problem being impacted by an inquiry (Cilliers, 2013). Complex problem solving can conjure new problems for teams as they attempt to anticipate future states, meet the conditions of the changing environment, while simultaneously dealing with interpersonal team challenges. Effective teams can counteract certain challenges by co-developing shared mental models and common goals that serve as a blueprint for bringing teams together toward a common purpose and hence targeted outcomes (Bennet, Gadlin, \& Levine-Finley, 2010; Cannon-Bowers et al., 1993; Tuckman, 1965; Tuckman \& Jensen, 1977). Lang et al. (2012) emphasize that the co-evolution of individuals and teams engaged in these sorts of endeavors is parallel to the complexity of the problems that teams are trying to solve and therefore requires similar skills to manage its complexity. This coevolution and social learning become part of the process in which complex problems may become more solvable as team interactions develop, change, and grow through intimacy with the complexity of the problem which they seek to solve through a process of social learning (Bandura, 1977; Schwandt, 2009). Framing of the problem and how a team might approach it may require team building techniques that respond to the wicked nature of problems being considered. This process will include management of the different types of knowledge (system, target, and transformational) that are required for addressing the problem.

The explicit problem focus in TDKPTs bridges human and natural systems related to a problem with little emphasis on the confines and boundaries found related to differing sectors, disciplines, and traditions of thought (Klein, 1996). This feature of TDKPTs views problems as multidimensional, void of the disconnections that can occur between theoretical and practical solutions (Wickson et al., 2006). As such, team members co-evolve in their understanding of abilities and skills along with the uncharted territory of the problem landscape as they become more facile in dealing with the shifting environment that it represents (Schwandt, 2009).

Transformative knowledge creation requires individual team members to operate in an environment that tests and challenges their ways of knowing, compels them to recognize and reconcile with conflicts, and creatively synthesize diverse knowledge bases. Such challenges can be overcome through individual and teaming behaviors that emphasize boundary crossing and build skills that are likely to 
forecast the future state of a problem (Weisbord, 2004), adaptability to emerging and changing perspectives that come from often challenging interpersonal interactions in teams (Entin \& Serfaty, 1999), and the ability to learn from the process of developing shared mental models (CannonBowers et al., 1993; Schwandt, 2009).

\section{A CASE OF TRANSDISCIPLINARY KNOWLEDGE PRODUCING TEAMS}

A report by Walsh and Wicks (2014), describes how students from multiple courses of study were introduced to a transdisciplinary approach geared toward understanding the complexity of wetland and coastal land loss in Louisiana, USA, through a field site experience at the Chenier Caminada near Port Fourchon. The problem was addressed from perspectives of three disciplines -- environmental management, geology, and landscape architecture. The integrative process required a multifold approach that incorporated different types of system knowledge about the river delta that informed and clarified the complexity of the overall problem. The course instructors challenged students to apply disciplinary knowledge (system knowledge) to a host of target particularities relating to landowner priorities, community needs, and geographical changes that could affect the overall long-term solutions to the complex problem of land erosion and loss (target knowledge). Ultimately, these areas of focal interest were to be applied to 5,10, and 25-year plans for the sustainability of the environment being studied leading to transformational knowledge that would integrate discipline-based knowledge of the environment in its present state with the diverse needs and concerns of those directly affected by the problem.

Instructors reported " ...change in attitude [about the extent of the geological problem] of the nongeology students when they developed a real understanding of the delta cycle. The final plans were truly transformative and integrative. The students understood how to link across disciplinary boundaries" (p. 51). However, this was not a unilateral experience across all disciplines involved, highlighting how team members co-evolve at different rates. Geology graduate students, presumably the most equipped with the target knowledge to address the problem, were found to be less confident in their teaming abilities after the teaming experience. The authors surmised that through the introduction of new perspectives, they, in fact, felt less equipped to tackle the problem. In other cases, where expertise was considered less developed, as in landscape architecture students, confidence in was even more diminished as a result of the project. As the instructors of the class reported, the abilities of students to share knowledge across boundaries within the project was heightened even though their confidence in their own teaming skills may have diminished as a result of the project (Walsh \& Wicks, 2014).

\section{STAKEHOLDER INVOLVEMENT}

While it can be easily surmised that multiple stakeholders representing different interests are needed to attempt complex problem solving, it is in the details of this sort of engagement where unique challenges emerge within TDKPTs. Interacting in ways that challenge unidisciplinary viewpoints requires an expansion of perspectives about the breadth of knowledge required in a process of inquiry and problem-solving. Conflicts arise usually as a result of the lack of facility in translating knowledge to ensure accessibility across a team of stakeholders (Bennett \& Gadlin, 2012). Maasen and Lieven (2006) find that these stifling dynamics can be observed when stakeholders representing both scientific and applied concerns interact and highlight "the separation between scientific expertise and policy-making" (p. 401).

The emphasis here is not on conflict, but rather the barriers that are the result of singularizing perspectives around a problem. It reminds us to consider the reasons for multi-stakeholder interaction. Multi-stakeholder engagement is key to complex problems solving (Roloff, 2008). In TDKPTs multistakeholder involvement arises from the need for task interdependence between actors to achieve a 
transdisciplinary end goal. If there is no interdependence between stakeholders within the system, there is no need for coordination across the system (Lawrence \& Lorsch, 1967; Thompson, 1967). Cohesion and interdependency amongst stakeholders stemming from their unique investments and agendas can be an opportunity for psychosocial investment in addressing a problem.

Differences in stakeholder understanding of problems in TDKPTs are not just a matter of the degree of involvement but also the ability to embrace the totality of the problem. The ability to integrate stakeholders with highly diverse perspectives including those who personally experience the problem is markedly different from that of other knowledge economies where knowledge production is left to those identified as knowledge specialists (Maasen \& Lieven, 2006). While the integration and synthesis of knowledge are of primary concern in these instances, such teaming engagements might lack the breadth of experiential knowledge to adequately engage all stakeholder perspectives. Translation between these factions requires an openness to seeking solutions across disciplines (Colditz et al., 2012) establishing interdependent relationships as the core basis teaming (Lawrence \& Lorsch, 1967). It is through the engagement of those who typically solve problems with those who typically are burdened with real-world problems where a unique stakeholder engagement specific to TDKPTs can be identified.

\section{METHODOLOGICAL PLURALISM}

Complex problem-solving depends on the freedom to employ multiple approaches toward understanding and resolving the problem, with no single methodological approach dominating problemsolving providing only a narrowly constructed solution (Wickson et al., 2006). If complex problem solving relies on a series of systematically and contextually related real-world factors, then solutions to these problems are just as complex. For this reason, no one method can adequately supply potential solutions. Constellations of methods are often employed in TDKPTs, and they coexist as do the multiple realities that emerge as part of the problems seeking to be solved (Nicolescu, 2005a). The logic behind this construction of problem-solving processes is antithetical to many traditional unidisciplinary means to problem-solving that rely on 'risk reduction' over 'risk production,' or the ability to gain insight through non-linear and often more conflict-laden perspectives. Similarly, conflict becomes an opportunity for knowledge production and boundary spanning. Increasing risk in problemsolving can be a means to expand the scope of the problem and seeking greater input from different actors toward the resolution of the problem (Maasen \& Lieven, 2006). This multi-method approach to problem-solving shows that more than one legitimate description of a problem exists and more than one potential solution is possible within a complex and adaptive system (Cilliers, 2013). Different descriptions will decompose the system in different ways and are not reducible to one another. Different descriptions may also have different degrees of complexity (Cilliers, 1998).

Environments that adopt multiple methods toward problem-solving are inherently complex. The adaptive nature of these environments will require the consideration of converging and diverging methodological practices and conflict may lead to both tension and creativity within the same teaming environment. When team members interface with different stakeholders and consider the ways in which they might utilize standardized methodologies from a host discipline in their quest to contribute to the solution of a problem, others will provide for complementary and possibly even contradictory ways of knowing and solving problems. As stated, this is a normative dynamic in a teaming environment where trust in methodological pluralism (Lamont \& Swidler, 2014), shifts in reality perceptions (Nicolescu, 2005a), and boundary spanning (Klein, 2004) is a constant state. Translation, therefore, becomes the dominant behavior in TDKPTs, where individuals and the team are continually challenged to show the relational characteristics between different methods and how through selection and hybridization they can provide novel approaches to complex problems (Larson, Landers, \& Begg, 2011). 


\section{PRAXIS}

The term praxis is an often-used word with many contextual underpinnings. Here we draw on the Aristotelian definition that emphasizes the relationship between thinking, making, and doing or transdisciplinary practice, knowledge, process, and application. The term was a key cornerstone in Marxist philosophy that challenged philosophical criticism to focus on the goals of philosophy to interpret the world for the sake of change and not just for the sake of critical analysis (Engels, 1886).

For the purposes of the consideration of praxis as a feature of TDKPTs one should think about praxis as a process unique to the TD form of inquiry that takes action, considers impact, analyzes through reflection, alters and revises plans, and then implements plans for future actions. The praxical orientation of TDKPTs is not unlike what Kolb (1984) refers to as the experiential learning cycle, one grounded in experiential learning as a cyclical process of concrete learning, reflective observation, abstract conceptualization and active experimentation. Here new experiences give way to personal reflection on how the experience affects the individual, and ultimately, abstraction and the application of new ideas into practice. This is an interplay between what some would refer to as the intersection of formal and informal knowledge, or that which is practiced and that which is experienced (Horlick-Jones \& Sime, 2004). This process is one where different forms of knowledge from divergent sources are related and reintegrated so as to represent a co-created knowledge form that is the result of the interactions between different components within a complex system (Cilliers, 2013). This reintegration results in evidence-based practical applications incorporated into scientific discourse. All the while this process also provides a means by which new ways of knowing and decisionmaking can be observed as the byproduct of a praxical approach (Lang et al., 2012). This process can contradict implementation science that is based on linear planning processes like those often found in scientific management (Taylor, 1911) that emphasize the product orientation of scientific inquiry for a more knowledge-based purpose for inquiry. Praxis provides the vehicle for moving beyond system knowledge (Hirsch Hadorn et al., 2007). It is the summation of the relationships and dimensionality of systems, target, and transformational knowledge states.

In many ways, praxis underpins how individuals and teams might embrace the transition from unidisciplinary knowledge to action-oriented transformational and applied knowledge that results in structural change. In light of the coexistent multiple perspectives that make up the transdisciplinary environment, praxis becomes the normative model for integrating multiplicity. Praxis assumes that theory and practice are related and each should inform each other in a reciprocal relationship. In itself, the achievement of a praxical orientation to knowledge building is a type of transdisciplinary endeavor. Wickson et al. (2006) state that transdisciplinary praxis "should co-evolve to a point where they are integrated and/or resonant. How this process proceeds in practice is one of the integrative challenges" (p. 1053) yet to be fully understood. However, it suggests that application and conceptualization are unified entities in the transdisciplinary process (Lotrecchiano, 2013).

\section{INTERACTIVE SYSTEMIC COMPLEXITIES}

\section{OPEN SYSTEMS CAPACITY}

The wicked problem-solving ability of teams rests on their capacity to operate as part of an open system (von Bertalanffy, 1956) allowing for knowledge from sources outside the system to permeate within the system and be considered alongside other types of knowledge. An open system presumes interactions with entities from outside of a group of bounded actors, ideas and/or entities with the intended result of recirculating knowledge through outputs back into the greater environment. Open systems are receptive to the input of tangible elements like resources and materials as well as the actors and ideas that are part of the input-output relationship between bounded systems (disciplines, teams, organizations, knowledge sets, etc.) and its interactions with other entities outside of it (Tress et al., 2003). The capacity to learn from this permeable environment and adapt behavior for better fit can enhance knowledge integration. Under these conditions, TDKPTs can integrate and synthesize 
disciplines by providing "synthetic reconfiguration of available knowledge regarding the social, economic, and ecological conditions" (Pregernig, 2006, p. 446).

In an open system environment, team members must expand the range of considerations beyond traditional outlets one is accustomed to. As input into a system occurs, conflict and power struggles between discipline-defined team members can emerge as traditional ways of knowing are challenged by the integration of approaches from outside system. Ideas and information are key environmental inputs in this kind of open system. When ideas and information are exchanged in a TD team, individuals' internal knowledge frameworks are challenged. This destabilizes the system and can lead to conflict. Engaging with the information, questioning one's own assumptions, reconciling with the limitations of the discipline, and finding ways to synthesize ideas toward the common problem, results in TD integration. These moments of tension and conflict are exchanges of information which represent 'triggers' of new awareness (Blau, 1964; Buckley, 1998) that have the potential to bring about novel awareness related to knowledge development (Eldridge \& Crombie, 1975). These energetic input-output boundary-spanning events highlight that TDKPTs "consist of patterned activities of a number of individuals and the activities are complementary or interdependent with respect to some common output or outcome" (Katz \& Kahn, 1966, p. 20) even though they may seem to be unrelated to a common goal as they are being played out. This exchanging of energy between individuals (interdependencies) within the system leads us to be able to identify the exchanges occurring within and without a system (Thompson, 1967).

A TDKPT working under these conditions deals with the challenge of including all necessary inputs. Such inclusion may foster and breed conflict, as the multiple inputs might require a team to behave in transparent and freely uninhibited ways. This feature draws our attention to the input-output mechanisms associated with all groups and organizations that must include knowledge from alternative sources and provide outputs that are targeted to multiple audiences. Here input-output interactions strive to develop a new integrated perspective (Katz \& Khan, 1996). This is a highly nonlinear pattern as outputs of these interactions is a function of future inputs. The state of the system is determined by the values of the inputs and outputs over time and in relation to the evolution of new problems within the same wicked problem (Cillers, 1998).

\section{DIFFERENT (SHIFTING) LEVELS OF REALITY}

One of the trademarks of scientific inquiry is the ability to frame and identify problems in light of their context within an agreed upon conceptual lens and analytic strategy (Burrell \& Morgan, 1979). TDKPTs engage in inquiry that challenges this trademark based on the possibility that in doing so a series of divergent realities can be considered alongside one another. Nicolescu (2006) describes the intersection of these sometimes oppositional or conflicting realities as a zone of non-resistance where human-based considerations like political, social, and individual realities intersect with natural realities like the environment, the cosmos, and physical law. This intersection is where exchanges in knowledge can flow freely (McGregor, 2011; Nicolescu, 2006). A systems perspective to complex problems includes experiences of multiple actors and approaches from a range of lenses that may suggest that multiple realities exist in problem-solving depending on one's proximity to it. In addition, reality itself can be skewed based on one's disciplinary lens or even the level of comfort one has with the complexity of a problem. Complex systems display reality over a diverse range of timescales, environmental landscapes, and experiential episodes (Cilliers, 2013).

As adaptive complex systems themselves, the network of actors involved in TDKPTs will display change as different stakeholders interface with one another, adjust their own disciplinary perspective, and contribute to new and emergent realities as part of their problem-solving efforts. Simultaneously, shifts occur within these complex systems as they adapt to a changing environment and self-organize themselves (Heylighen, 2008). This is necessary in order for the system to cope with its environment, and in TDKPTs this adaptation brings teams closer to considering problems with a more holistic 
viewpoint. Change is at the heart of such systemic emergence, and it is a constant state that requires adaptation as a constant function (Barnes, Matka, \& Sullivan, 2003; Cilliers, 2013; Nicolescu, 2010).

Complex systems like those represented in TDKPTs display behaviors that are a direct result of interactions between actors and the knowledge being generated. In other words, the goal of generating new knowledge is more dependent on processes of creating knowledge, even if measured using different or divergent realities, than solely the synthesis of existing knowledge. Emergence is key to this feature as the goal of TDKPTs is to develop holistic approaches that are not subject to the parts of disciplines that make them up but rather are the culmination of including multiple states of reality related to a problem. As such, the environment of these teams can be one of disorientation where the environment is a constantly changing reality requiring individuals to develop skills that are multidimensional and access multiple states of reality as perceived through different stakeholders.

\section{COLLABORATIVE DECONSTRUCTION AND RECONSTRUCTION}

As teams work toward affecting new arrangements of knowledge in their problem-solving activities, new arrangements of collaborators and stakeholders emerge (Wickson, 2006). This is partly due to inclusiveness and partly due to the creation of novel approaches and insights that may not lie within the perceived boundaries of a given problem. This process of boundary spanning in the interpretation of the complexity of problems invites new relationships between stakeholders that may be unusual or novel either because of their novel disciplinary arrangement or because of the viewpoint they may bring to solving the problem (Balsiger, 2004). Often these unexpected relational arrangements are the result of involving those who are directly affected by problems to work along those who merely work to solve problems (Klein, 2004). Such construction of relationships can often deconstruct others and create strong ties out of loosely constructed ones (Simmel, 1955).

Active exchanges between professionals of different disciplines or even from the same traditions can develop into novel interdependencies (Thompson, 1967). As coordination and collaboration develop into new interdependencies between actors of the system increasing complexity of these relationships can support a reordering of the collaborative functions between those who work together in the same team (Maasen \& Lieven, 2006). These relationships may become more asymmetric than equal as team construction becomes a reflection of the complex environment in which the team works adapting to complex arrangements of relationships through an internal dynamic process. Overall team structure is maintained even though the components themselves are exchanged or renewed (Cilliers, 2013).

Groups, where changes in relationships and the strengthening and weakening of ties is a normative activity, can make for a challenging team environment. The consequences of these dynamics in parallel with the shifting landscape of problems and their solution seeking processes can cause emotional strain to existing relationships as disciplinary communal ties are tested and reshaped. There may even be emotional stresses requiring stakeholders to reevaluate their dedication to a strain of thought and the relationships with stakeholders that constitute one's loyalty. Such shifts can result in dissension from one's previously espoused epistemological commitments and require mediation and reflective skills as team members adapt through recombination. Recombination is the process of taking existing compositions and breaking them down into constituent elements and recombining them to form new ones (Kerne, 2005). Such reorganization of one's placement in the system of knowledge often results in reevaluating team values and can result in modifying behaviors to better navigate these relational changes. 


\section{CONCLUSION: VIEWING TRANSDISCIPLINARY LEARNING AND ENGAGEMENT THROUGH A COMPLEXITY LENS}

Unique to transdisciplinarity is the evolution of integrated and synthesized knowledge beyond the boundaries that often separate it. The challenge is to involve participants in the theoretical, epistemological, and methodological evolutions that are the source and summit of transdisciplinary communication and collective learning. Baiyin Yang's description of learning environments that accept the social dynamism embedded in knowledge integration is in concert with TDKPTs and is useful for a discussion on bridging the gap between structural and interactive system complexities. It supports the expectation that knowledge production is an enterprise of change, learning, and influence by multiple agents, not all of which are human actors. TD learning, with its social, conceptual, behavioral and psychological facets, hints at describing settings where "knowledge is defined as human beings' understanding about reality through mental correspondence, personal experience, and emotional affectation with outside objects and situations" (Yang, 2003, p. 108) not solely focusing on behavior or traits.

The mechanisms of how TD learning can be observed and operationalized on the individual level may inform collective efficacy and communities of practice once uncovered in more detail. Some work has been conducted already in this area. The structural relationship between personal selfefficacy and collective efficacy have been studied in light of change, socio-economic status and communal activity resulting in conversations about the role of individuals in collective work groups (Fernandez-Ballestros, Diez-Nicolas, Caprara, Barbaranelli, \& Bandura, 2002). "Micro social order" has been proposed as a link to collective-oriented behavior, positive affect, and group perceptions into a network that generates recurrent patterns of exchange (Lawler, Thye, \& Yoon, 2008). Research on collective efficacy and its measurement has been taken up by Roger Goddard who, while focusing on collective belief, has also begun to consider the individual in light of collective efficacy (Goddard, 2002; Goddard, Hoy, \& Hoy, 2004). Some studies have been conducted that attempt to show the impact of individual interactions on collective efficacy with teachers and principals (Wahlstrom \& Seashore Louis, 2008) in leader verbal behavior (Sims \& Manz, 1984) and in multi-agency work settings (Daniels, Leadbetter, \& Warmington, 2007; Stokols et al., 2003; Stokols, Hall, Taylor, \& Moser, 2008; Stokols, Misra, Moser, Hall, \& Taylor, 2008)

Another theoretical area in need of attention is that of the role of cognitive dissonance within reciprocal interactions. The role of dissonance, and more importantly the consequences of gravitation toward psychological consonance has a direct effect on the achievement of TD learning with its requirement for maintaining multiple realities and conversations. As Leon Festinger has claimed, "the reality which impinges on a person will exert pressures in the direction of bringing the appropriate cognitive elements into correspondence with that reality" (Festinger, 1957, p. 11). Scholars in the area of cognitive dissonance have been more active in their attempt at focusing on how dissonance affects the individual learner and empirical studies range from intragroup studies on agree-

ment/disagreement dynamics (Glasford, Pratto, \& Dovidio, 2008; Matz \& Wood, 2005), to workplace learning behavior (Dechawatanapaisal \& Siengthai, 2006), and to behavior regulation through devaluation of positive stimuli (Veling, Holland, \& van Knippenberg, 2008). Even in these rigorous studies, a match between research on individual learning mechanisms and TD settings is lacking.

For a context-specific research paradigm which focuses on individual learning mechanisms in the context of TD settings, scholars will need to construct their endeavors in ways similar to the tenets of TD settings themselves: interpenetration of epistemologies, methodological pluralism, shifting realities, etc. In fact, most of the work in dissecting TD has been conducted in the realm of research paradigms, and the TD characteristics suggested in this paper stem from those inquiries. Scholars need to ask questions of the problem with phenomenological and cybernetic lenses (Brier, 2003; Nicolescu, 1995) that by their very nature, are better equipped to harvest the multilayered data in intersecting phenomena that are in constant dynamic flux. Social mechanisms may serve well as dy- 
namic variables in these sorts of studies where changing interactive indicators are used to establish codes and themes more suited than static variables for research (Hëdstrom, 2005; Hedström \& Swedberg, 1998). Worth noting are the successful attempts of scholars like Grandon Gill, of the University of South Florida, and Eli Cohen, of the Informing Science Institute, who have recently proposed research techniques on individual coping with complexity and its effect on information processing that are highly adaptable to TD settings (Gill \& Cohen, 2008).

If individual learning in complex TD settings is to be understood for the purpose of enlightening practical leadership, a variety of contributions will need to be synthesized focusing on real-life TD situations. At the moment, these are limited or at least underdeveloped. However, many sectors like cancer research (Croyle, 2008; Hiatt \& Breen, 2008; Sellers, Caporaso, Lapidus, Peterson, \& Trent, 2006), tobacco and substance abuse research (Abrams, Leslie, Mermelstein, Kobus, \& Clayton, 2003; G. Morgan, Kobus, \& Gerlach, 2003; Provan, Clark, \& Huerta, 2008; Unger et al., 2003), aerospace technology development (Jeffrey, Allen, \& Seaton, 2000), and translational team science (Morrison, 2008; National Center for Research Resources, 2010) are paving the way. The conclusion to any conversation about TD learning must ultimately return to the question of the models, structure, and characteristics of TD environments but also must include the individual psychosocial functioning that provides individual access to these sorts of social and conceptual interactions.

Wickson et al. (2006) suggest that reflection is a necessary skill for transdisciplinary engagement for it encourages participants to assess frames of reference, values, beliefs, and assumptions in light of emerging problems and solutions rather than simply being observational in the process of problemsolving. This leads to full participation in the development of methods of investigation and learning.

By defining the features of TDKPTs, we are able to consider the role of complexity theory in researching such teams, while simultaneously considering the skills needed to work within TD teams. Ultimately, these features draw our attention to the role of communication in knowledge generation. Such research takes seriously the need to understand team dynamics, explores research methodologies that can uncover the social nature of knowledge producing teams, and deciphers the indicators of their productivity from the standpoint of transdisciplinary knowledge generation. While research on communication in TD teams continues to be elusive and partially lacking rigor, scholars can inform the major challenges that transdisciplinary teams face on a regular basis: integration, praxis, and engagement by examining the functional and cognitive elements of teaming behavior both at onset and during teaming engagement. This is particularly important for multiple stakeholder projects with scientific, practice and community implications as problems and priorities are sure to emerge over time with the changing state of a system and as team members change and co-evolve with their wicked problems. Evaluation methodologies used with scientific and practice participants may be challenged to clearly capture both practitioner and researcher scientist perspectives which at times may represent opposing viewpoints because of their own temporal biases.

\section{REFERENCES}

Abrams, D., Leslie, F., Mermelstein, R., Kobus, K., \& Clayton, R. (2003). Transdisciplinary tobacco use research. Nicotine and Tobacco Research, 5(S1), S5-S10. https://doi.org/10.1080/14622200310001625519

Allan, K. (2007). The social lens: An invitation to the social and sociological theory. Thousand Oaks CA: Pine Forge Press.

Balsiger, P. (2004). Supradisciplinary research practices: History, objectives and rationale. Futures, 36(4), 407-421. https://doi.org/10.1016/i.futures.2003.10.002

Bandura, A. (1977). Social learning theory. Upper Saddle River, NJ: Prentice Hall.

Barnes, M., Matka, E., \& Sullivan, H. (2003). Evience, understanding and complexity. Evaluation, 9(3), 265-284. https://doi.org/10.1177/13563890030093003 
Features of TDKPTs

Bear, J., \& Woolley, A. (2013). The role of gender in team collaboration and performance. Interdisciplinary Science Reviews, 36(2), 146-153. https://doi.org/10.1179/030801811X13013181961473

Becher, T. (1990). The counter culture of specialization. European Journal of Education, 25(2), 333-346. https://doi.org/10.2307/1503322

Bedwell, W., Wildman, J., DiazGranados, D., Salazar, M., Kramer, W., \& Salas, E. (2012). Collaboration at work: An integrative multilevel conceptualization. Human Resource Management, 22(2), 128-145. https://doi.org/10.1016/i.hrmr.2011.11.007

Bennet, L. M., Gadlin, H., \& Levine-Finley, S. (2010). Collaboration and team science: A field guide. Bethesda, Maryland, USA: NIH Office of the Ombudsman, Center for Cooperative Resolution. Retrieved from https://www.researchgate.net/profile/Samantha LevineFinley/publication/220041906 Collaboration and Team Science A Field Guide/links/00b7d5283ce8d 9092e000000.pdf

Bennett, L., \& Gadlin, H. (2012). Collaboration and team science. Journal of Investigative Medicine, 60(5), 768. https://doi.org/10.2310/JIM.0b013e318250871d

Blau, P. (1964). Exchange and power in social life. New York: J. Wiley.

Boon, C., Den Hartog, D., Boselie, P., \& Paauwe, J. (2011). The relationship between perceptions of HR practices and employee outcomes: Examining the role of person-organisation and person-job fit. International Journal of Human Resource Management, 22(1), 138-162. https://doi.org/10.1080/09585192.2011.538978

Borner, K., Contractor, N., Falk-Krzesinski, H. J., Fiore, S., Hall, K., Keyton, J., \& Uzzi, B. (2010). A multi-level stystems perspective for the science or team science. Science Translational Medicine, 2(49), 1-5. https://doi.org/10.1126/scitranslmed.3001399

Brier, S. (2003). Cybersemiotics and the question of semiotic and informational thresholds. World Futures, 59 , 361-380. https://doi.org/10.1080/02604020310116

Brown, V., Harris, J., \& Russell, J. (2010). Tackling wicked problems: Through the transdisciplinary imagination. London: Earthscan.

Buckley, W. (1998). Society: A complex adaptive system. Essays in social theory. Gordon and Breach.

Burnes, B. (2005). Complexity theories and organizational change. International Journal of Management Reviews, 7(2), 72-90. https://doi.org/10.1111/j.1468-2370.2005.00107.x

Burrell, G., \& Morgan, G. (1979). Sociological paradigms and organisational analysis: Elements of the sociology of corporate life. London: Heinemann.

Cannon-Bowers, J., Salas, E., \& Converse, S. (1993). Shared mental models in expert team decision making. In N. Castellan (Ed.), Current issues in individual and group decision making (pp. 221-246). Mahwah, NJ: Erlbaum.

Choi, B. C. K., \& Pak, A. W. P. (2007). Multidisciplinarity, interdisciplinarity, and transdisciplinarity in health research, services, education and policy: 2. Promotors, barriers, and strategies of enhancement. Clinical \& Investigative Medicine, 30(6), E224-E232. https://doi.org/10.25011/cim.v30i6.2950

Cilliers, P. (2013). Complexity and postmodernism. Understanding complex systems. In C. Martin \& J. Strumberg (Eds.), Handbook of systems and complexity in health. New York: Springer. https://doi.org/10.1007/978-1-4614-4998-0 3

Colditz, G., Wolin, K., \& Gehlert, S. (2012). Applying what we know to accelerate cancer prevention. Science Translational Medicine, 4(127), 127rv124. https://doi.org/10.1126/scitranslmed.3003218

Cooke, N., \& Hilton, M. (2015). Enhancing the effectiveness of team science. Washington, DC: National Academies Press.

Crowston, K., Specht, A., Hoover, C., Chudoba, K., \& Watson-Manheime, M. (2015). Perceived discontinuities and continuities in transdisciplinary scientific working groups. Science of the Total Environnmennt, 534, 159172. https://doi.org/10.1016/j.scitotenv.2015.04.121 
Croyle, R. (2008). The National Cancer Institute's transdisciplinary centers initiaives and ther need for building a science of team science. American Journal of Preventative Medicine, 35(2S), S90-S93. https://doi.org/10.1016/j.amepre.2008.05.012

Daniels, H., Leadbetter, J., \& Warmington, P. (2007). Learning in and for multi-agency working. Oxford Review of Education, 33(4), 521-538. https://doi.org/10.1080/03054980701450811

Dechawatanapaisal, D., \& Siengthai, S. (2006). The impact of cognitive dissonance on learning work behavior. Journal of Workplace Learning, 18(1/2), 42-54. https://doi.org/10.1108/13665620610641300

Dillon, P. (2008). A pedagogy of connection and boundary crossings: methodological and epistemological transactions in working across and between disciplines. Innovations in Education, 45(3), 255-262. https://doi.org/10.1080/14703290802176121

Eldridge, J., \& Crombie, A. (1975). A sociology of organisations. New York: International Publications Service.

Engels, F. (1886). Marx/Engels selected works (Vol. 1). Moscow, USSR: Progress Publishers.

Entin, E., \& Serfaty, D. (1999). Adaptive team coordination. Human Factors The Journal of the Human Factors and Ergonomics Society, 41 (2), 312-325. https://doi.org/10.1518/001872099779591196

Fernandez-Ballestros, R., Diez-Nicolas, J., Caprara, G. V., Barbaranelli, C., \& Bandura, A. (2002). Determinants and structural relations of personal efficacy and collective efficacy. Applied Psychology: An International Reviem, 51(1), 107-125. https://doi.org/10.1111/1464-0597.00081

Festinger, L. (1957). A theory of cognitive dissonance. Stanford, CA: Stanford University Press.

Fine, H. (2007). Transdisciplinarity: trying to cross boundaries. Tamara Journal of Critical Organisation Inquiry, $6(3 / 4), 16$.

Gibbons, M., Limoges, C., Nowotney, H., Schwartzman, S., Scott, P., \& Trow, M. (1994). The new production of knoweldge: The dynamics of science and research in contemporary societies. London: SAGE.

Gill, T., \& Cohen, E. (2008). Research themes in complex informing. Informing Science: The International Journal of an Emerging Transdiscipline, 11, 147-164. https://doi.org/10.28945/444

Glasford, D., Pratto, F., \& Dovidio, J. (2008). Intragroup dissonance; Responses to ingroup violation and personal values. Journal of Experimental Social Psychology, 44, 1057-1064. https://doi.org/10.1016/i.jesp.2007.10.004

Goddard, R. (2002). A theoretical and empirical analysis of the measurement of collective efficacy: A development of a short form. Educational and Psychological Measurement, 62(1), 97-110. https://doi.org/10.1177/0013164402062001007

Goddard, R., Hoy, W., \& Hoy, A. (2004). Collective efficacy beliefs: theoretical developments, empirical evidence, and future direction. Educational Researcher, 33(3), 3-13. https://doi.org/10.3102/0013189X033003003

Gray, B. (2008). Enhancing transdisciplinary research through collaborative leadership. American Journal of Preventative Medicine, 35(2S), S124-132. https://doi.org/10.1016/i.amepre.2008.03.037

Graybill, J., Dooling, S., Vivek, S., \& John, W. (2006). A rough guide to interdisciplinarity: Graduate student perspectives. Bioscience, 56(9), 757. https://doi.org/10.1641/0006-3568(2006)56[757:ARGTIG]2.0.CO;2

Hagemeier-Klose, M., Beichler, S., Davidse, B., \& Deppisch, S. (2004). The dynamic knowledge loop: Inter- and transdisciplinary cooperation and adaptation of climate change knowledge. International Journal of Disaster Risk Science, 5(1), 21-32. https://doi.org/10.1007/s13753-014-0015-4

Hall, K., Stokols, D., Stipelman, B., Vogel, A., Feng, A., Masimore, B., . . Berrigan, D. (2012). Assessing the value of team science: A study comparing center- and investigator-initiated grants. American Journal of Preventative Medicine, 42(2), 157-163. https://doi.org/10.1016/j.amepre.2011.10.011

Hammond, R., \& Dubé, L. (2012). A systems science perspective and transdisciplinary models for food and nutrition security. PNAS, 109(31), 12356-12363. https://doi.org/10.1073/pnas.0913003109 
Features of TDKPTs

Hedström, P. (2005). Dissecting the social. Cambridge, MA: Cambridge University Press. https://doi.org/10.1017/CBO9780511488801

Hedström, P., \& Swedberg, R. (1998). Social mechanisms: An analytic approach to social theory. Cambridge: Cambridge University Press. https://doi.org/10.1017/CBO9780511663901

Heylighen, F. (2008). Complexity and self-organization. In M. Bates \& M. Maack (Eds.), Encyclopedia of library and information sciences (pp. 1215-1224). Taylor and Francis.

Hiatt, R., \& Breen, N. (2008). The social determinants of cancer. American Journal of Preventative Medicine, 35(2S), S141-S150. https://doi.org/10.1016/i.amepre.2008.05.006

Hirsch Hadorn, G., Hoffmann-Riem, H., Biber-Klemm, S., Grossenbacher-Mansuy, W., Joye, D., Pohl, C., \& Zemp, E. (2007). Handbook of transdisciplinary research: Springer.

Horlick-Jones, T., \& Sime, J. (2004). Living on the border: Knowledge, risk and transdisciplinarity. Futures, 36(4), 441-456. https://doi.org/10.1016/i.futures.2003.10.006

Huutoniemi, K., Klein, J., Bruun, H., \& Hukkinen, J. (2010). Analyzing interdisciplinarity: Typology and indicators. Research Policy, 39(1), 79-88. https://doi.org/10.1016/i.respol.2009.09.011

International Center for Transdisciplinary Research. (2018). CIRET. Retrieved from http://cirettransdisciplinarity.org/index en.php

Jantsch, E. (1972a). Inter- and transdisciplinary university: A system approach to education and innovation. Higher Education, 1(1), 7-37. https://doi.org/10.1007/BF01956879

Jantsch, E. (1972b). Toward interdisciplinarity and transdisciplinarity in education and innovation. . Paper presented at the Center for Education Research and Innovation (CERI), Paris, France.

Jeffrey, P., Allen, P., \& Seaton, R. (2000). Cross-disciplinary knoweldge as a guide to the study and management of complexity: The case of product definition in the aerospace industry. Paper presented at the International Transdisciplinarity Conference, Zurich, Switzerland.

Jones, B. F., Wuchty, S., \& Uzzi, B. (2008). Multi-university research teams: Shifting impact, geography, and stratification in science. Science, 322, 1259-1262. https://doi.org/10.1126/science.1158357

Katz, D., \& Kahn, R. (1966). The social psychology of organizations. New York: Wiley.

Klein, J. (1990). Interdisciplinarity: History, theory, and practice. Detroit: Wayne State University Press.

Klein, J. (1996). Crossing boundaries: Knowledge, disciplinarities, and interdisciplinarities. Charlottesville, VA.: University Press of Virginia.

Klein, J. (1998). The discourse of interdisciplinarity. Liberal Education, 84(3), 4.

Klein, J. (2004). A platform for a shared discourse of interdisciplinary education. Paper presented at the Fenner Conference on the Environment, Guadalajara, Mexico.

Klein, J. (2014). Inter- and trans-disciplinary boundary work in collaboration science and translational medicine. Journal of Translational Medicine and Epidemiology, 2 (Special Issue: Collaboration Science and Translational Medicine), 1024-1030.

Kockelmans, J. (1979). Why interdisciplinarity? In J. Kockelmans (Ed.), Interdisciplinarity in higher education (pp. 123-160). Pennsylvania State University Press.

Kolb, D. (1984). Experiential learning: Experience as the source of learning and development. Prentice Hall.

Kuhn, T. (1970). The structure of scientific revolutions (2d ed.). Chicago: University of Chicago Press.

Kyvik, S., \& Teigen, M. (1996). Child care, research collaboration, and gender differences in scientific productivity. Science, Technology, and Human Values, 21(1), 54-71. https://doi.org/10.1177/016224399602100103

Lamont, M., \& Swidler, A. (2014). Methodological pluralism and the possibilities and limits of interviewing. Qualitative Sociology, 37(2). https://doi.org/10.1007/s11133-014-9274-z 
Lang, D., Wiek, A., Bergmann, M., Stauffacher, M., Martens, P., Moll, P., .. . Thomas, C. (2012).

Transdisciplinary research in sustainability science: Practice, principles, and challenges. Sustainability Science, 7(1), 25-43. https://doi.org/10.1007/s11625-011-0149-x

Larson, E., Landers, T., \& Begg, M. (2011). Building interdisciplinary research models: A didactic course to prepare interdisciplinary scholars and faculty. Clinical Translational Science, 4(1), 38-41. https://doi.org/10.1111/i.1752-8062.2010.00258.x

Lawler, E., Thye, S., \& Yoon, J. (2008). Social exchange and micro social order. American Sociological Review, 73(August), 519-542. https://doi.org/10.1177/000312240807300401

Lawrence, P., \& Lorsch, J. (1967). Organization and environment; Managing differentiation and integration. Boston: Division of Research, Graduate School of Business Administration, Harvard University.

Lotrecchiano, G. (2010). Complexity leadership in transdisciplinary (TD) learning environments: A knowledge feedback loop. International Journal of Transdisciplinary Research, 5(1), 29-63.

Lotrecchiano, G. (2011). Leadership is as simple as a game of marbles: Transdisciplinary, learning and complexity in fairies, keepsies and mibs. Integral Leadership Review, 11(1). Retreived from http://integralleadershipreview.com/2011/2008/leadership-is-as-simple-as-a-child $\%$ e2012\%2080\%2099sgame-of-marbles/.

Lotrecchiano, G. (2012). Social mechanisms of team science: A descriptive case study using a multilevel systems perspective employing reciprocating struturation theory. (EdD thesis), George Washington University, Washington DC.

Lotrecchiano, G. (2013). A dynamical approach toward understanding mechanisms of team science: Change, kinship, tension, and heritage in a transdisciplinary team. Clinical and Translational Science, 6(4), 267-278. https://doi.org/10.1111/cts.12054

Lotrecchiano, G., Mallinson, T., Leblanc-Beaudoin, T., Schwartz, L., Lazar, D., \& Falk-Krzesinski, H. (2016). Motivation and threat indicators for collaboration readiness in knowledge generating teams (KPTs): A scoping review and domain analysis. Heliyon, 2(5). https://doi.org/10.1016/i.heliyon.2016.e00105

Maasen, S., \& Lieven, O. (2006). Transdisciplinarity: a new mode of governing science? Science \& Public Policy (SPP), 33(6), 399-410. https://doi.org/10.3152/147154306781778803

Matz, D., \& Wood, W. (2005). Cognitive dissonance in groups; The consequences of disagreement. Journal of Personality and Social Psychology, 88(1), 22-37. https://doi.org/10.1037/0022-3514.88.1.22

Maxwell, J. A. (2005). Qualitative research design. Thousand Oaks, CA: SAGE Publications.

McGregor, S. (2011). Demystifying transdisciplinary ontology: Multiple levels of reality and the hidden third Integral Leadership Review. Retrieved from http://integralleadershipreview.com/1746-demystifyingtransdisciplinary-ontology-multiple-levels-of-reality-and-the-hiddenthird

Mickan, M., \& Rodger, S. (2005). Effective health care teams: A model of six characteristics developed from shared perceptions. Journal of Interprofessional Care, 19(4), 358-370. https://doi.org/10.1080/13561820500165142

Misra, S., Stokols, D., \& Cheng, L. (2016). The transdisciplinary orientation scale: Factor structure and relation to the integrative quality and scope of scientific publications. Journal of Translational Medicine and Epidemiology, 3(2), 1042.

Morgan, G., Kobus, K., \& Gerlach, K. (2003). Facilitating transdiciplinary research: The experience of the transdisciplinary tobacco use research centers. Nicotine and Tobacco Research, 5(1S), S11-S19. https://doi.org/10.1080/14622200310001625537

Morgan, N. (2002). Notions of transdisciplinarity. In M. Somerville \& D. Rapport (Eds.), Transdisciplinarity: Recreating Integrated Knowledge (pp. 38-41). Oxford, UK: EOLSS Publishers.

Morrison, L. (2008). The CTSAs, the Congress, and the scientific method. Journal of Investigative Medicine, 56, 710. https://doi.org/10.2310/jim.0b013e31816254b4

National Center for Research Resources, N. (2010). Clinical and translational science awards. Retrieved from http://www.ncrr.nih.gov/clinical research resources/clinical and translational science awards/ 
National Science Foundation. (2018). Convergence research at NSF. Retrieved from https://www.nsf.gov/od/oia/convergence/index.jsp

Nicolescu, B. (1995). Cybernetics: The bridge between divided knowledge and transdisciplinarity. Kybernetes: The International Journal of Systems and Cybernetetics, 24(7), 21-24. https://doi.org/10.2310/jim.0b013e31816254b4

Nicolescu, B. (2002). Manifesto of transdisciplinarity (K.-C. Voss, Trans.). Albany, NY: State University of New York Press.

Nicolescu, B. (2005a). Towards a transdisciplinary education. The Journal for Transdisciplinary Research in Southern Africa, 1(1), 5-16. https://doi.org/10.4102/td.v1i1.300

Nicolescu, B. (2005b). Towards transdisciplinary education and learning. Paper presented at the Science and Religion: Global Perspectives, Philadelphia, PA.

Nicolescu, B. (2006). Hidden Third Theory. In B. Haverkott \& C. Reijntjes (Eds.), Moving Worldviews Conference Proceedings (pp. 142-165). Leusden, the Netherlands: ETC/Compas.

Nicolescu, B. (2010). Methods of transdisciplinarity-Levels of reality, logic of the included middle and complexity. Transdisciplinary Journal of Engineering \& Science, 1(1), 19-38.

Nicolescu, B. (2012). Transdisciplinarity: The hidden third, between the subject and the object. Human and Social Studies, 1(2), 13-28. https://doi.org/10.2478/v10317-012-0002-5

Paletz, S. B., \& Schunn, C. (2010). A social-cognitive framework of multidisciplinary team innovation. Topics in Cognitive Science, 2, 73-95. https://doi.org/10.1111/j.1756-8765.2009.01029.x

Park, J.-Y., \& Son, J.-B. (2010). Transitioning toward transdisciplinary learning in a multidisciplinary environment. International Journal of Pedagogies and Learning, 6(1), 82-93. https://doi.org/10.5172/ijpl.6.1.82

Piaget, J. (1972). The epistemology of interdisciplinary relationships. Paper presented at the Center for Educational Research and Innovation (CERI), Paris, France.

Pirrie, A., Wilson, V., \& Elsewood, J. (1998). Evaluating multidisciplinary education in health care. Edinburgh: The Scottish Council for Research in Education.

Plsek, P., \& Wilson, T. (2001). Complexity science: Complexity, leadership, and management in healthcare organizations. British Medical Journal, 323(7315), 746-749. https://doi.org/10.1136/bmj.323.7315.746

Powell, W., \& Snellman, K. (2004). The knowledge economy. Annual Review of Sociology, 30, 199-220. https://doi.org/10.1146/annurev.soc.29.010202.100037

Pregernig, M. (2006). Transdisciplinarity viewed from afar: Science-policy assessments as forums for the creation of transdisciplinary knowledge. Science \& Public Policy (SPP), 33(6), 445-455. https://doi.org/10.3152/147154306781778867

Provan, K., Clark, P., \& Huerta, T. (2008). Transdisciplinarity among tobacco harm-reduction researchers. American Journal of Preventative Medicine, 35(2S), S173-181. https://doi.org/10.1016/j.amepre.2008.05.015

Repko, A., \& Szostak, R. (2016). Interdisciplinary research: Process and theory: SAGE.

Roloff, J. (2008). A life cycle model of multi-stakeholder networks. Business Ethics: A European Review, 17(3), 311 325. https://doi.org/10.1111/j.1467-8608.2008.00537.x

Rosenfield, P. (1992). The potential of transdisciplinary research for sustaining and extending linkages between the health and social sciences. Social Science and Medicine, 25(11), 1343-1357. https://doi.org/10.1016/02779536(92)90038-R

Salas, E., Shuffler, M., Thayer, A., Bedwell, W., \& Lazzarra, E. (2015). Understanding and improving teamwork in organizations: A scientifically based practical guide. Human Resource Management, 54(4), 599-622. https://doi.org/10.1002/hrm.21628

Schwandt, D. (2008). Individual and collective coevolution. In M. Uhl-Bein \& R. Marion (Eds.), Complexity leadership, Part 1: Conceptual foundations. Charlotte: IAP Publications. 
Schwandt, D. (2009). Collective learning as social change: Integrating complex adaptive systems and structuration with Parsons's theory of action. In C. Hart (Ed.), Essays in honor of Talcott Parsons (pp, 125150). Poynton: Midrash Publications.

Sellers, T., Caporaso, N., Lapidus, S., Peterson, G., \& Trent, J. (2006). Opportunities and barriers in the age of team science. Cancer Causes \& Controls, 17(3), 229-237. https://doi.org/10.1007/s10552-005-0546-5

Shuffler, M., DiazGranados, D., \& Salas, E. (2011). There's a science for that: Team development interventions in organizations. Current Directions in Psychological Science, 20(6), 365-372. https://doi.org/10.1177/0963721411422054

Simmel, G. (1955). Conflict. New York: Free Press.

Sims, H., \& Manz, C. (1984). Observing leader verbal behavior; Toward reciprocal determinism in leadership theory. Journal of Applied Psychology, 69(2), 222-232. https://doi.org/10.1037/0021-9010.69.2.222

Somerville, M., \& Rapport, D. (2002). Transdiciplinarity: reCreating integrated knowledge.

Stokols, D., Fuqua, J., Gress, J., Harvey, R., Phillips, K., Baezconde-Garbanati, L., . . Trochim, W. (2003). Evaluating transdisciplinary science. Nicotine and Tobacco Research, 5(S1), S21-S39. https://doi.org/10.1080/14622200310001625555

Stokols, D., Hall, K., Taylor, B., \& Moser, R. (2008). The science of team science. American Journal of Preventative Medicine, 35(2S), S77-S88. https://doi.org/10.1016/j.amepre.2008.05.002

Stokols, D., Misra, S., Moser, R., Hall, K., \& Taylor, B. (2008). The ecology of team science. American Journal of Preventative Medicine, 35(2S), S96-S115. https://doi.org/10.1016/j.amepre.2008.05.003

Thompson, J. (1967). Organizations in action: Social science bases of administrative theory. New York: McGraw Hill.

Tress, M., Tress, G., \& Fry, G. (2003). Potential and limitations of interdisciplinary and transdisciplinary landscape studies. Wageningen: Delta Program.

Tuckman, B. (1965). Developmental sequence in small groups. Psychological Bulletin, 63(6), 384. https://doi.org/10.1037/h0022100

Tuckman, B., \& Jensen, M. (1977). Stages of small group development revisited. Group and Organization Studies, 2(4), 419-427. https://doi.org/10.1177/105960117700200404

UNESCO. (1998). Transdisciplinarity: Stimulating synergies, integrating knowledge. Paper presented at the Division of Philosophy and Ethics, Royaumont Abbey, Val-d'Oise, France. Available at http://unesdoc.unesco.org/images/0011/001146/114694eo.pdf

Unger, J., Cruz, T., Shakib, S., Mock, J., Shields, A., Baezconde-Garbanati, L., . . Johnson, C. (2003). Exploring the cultural context of tobacco use: A transdisicplinary framework. Nicotine and Tobacco Research, 5(Supplement 1), S101-S117. https://doi.org/10.1080/14622200310001625546

Veling, H., Holland, R., \& van Knippenberg. (2008). When approach motivation and behavioral inhibition collide; Behavior regulation through stimulus devaluation. Journal of Experimental Social Psychology, 44, 10131019. https://doi.org/10.1016/i.jesp.2008.03.004

von Bertalanffy, L. (1956). General systems theory. General Systems, 1, 1-10.

Wahlstrom, K., \& Seashore Louis, K. (2008). How teachers experience principal leadership: The roles of professional community, trust, efficacy, and shared responsibility. Educational Administration Quarterly, 44(4), 458-495. https://doi.org/10.1177/0013161X08321502

Walsh, M., \& Wicks, C. (2014). Introducing transdisciplinary problem solving to environmental management systems and geology students through a case study of disturbed coastal systems. Journal of College Science Teaching, 43(3), 48-53. https://doi.org/10.2505/4/jcst14 $043 \quad 03 \quad 48$

Walter, A., Helgenberger, S., Wiek, A., \& Scholz, R. (2007). Measuring societal effects of transdisciplinariy research projects: Design and application of an evaluation method. Evaluation and Program Planning, 30, 325338. https://doi.org/10.1016/j.evalprogplan.2007.08.002 
Weisbord, M. (2004). Productive workplaces revisited: Dignity, meaning, and community in the 21st century. San Francisco: Jossey-Bass.

Wheatley, M. (1999). Leadership and the new science. San Francisco: Berrett-Koehler.

Wickson, F., Carew, A., \& Russell, A. (2006). Transdisciplinary research: Characteristics, quandaries and quality. Futures, 38, 1046-1059. https://doi.org/10.1016/i.futures.2006.02.011

Yang, B. (2003). Toward a holistic theory of knowledge and adult learning. Human Resource Development Review, 2(2), 106-129. https://doi.org/10.1177/1534484303002002002

\section{BIOGRAPHIES}

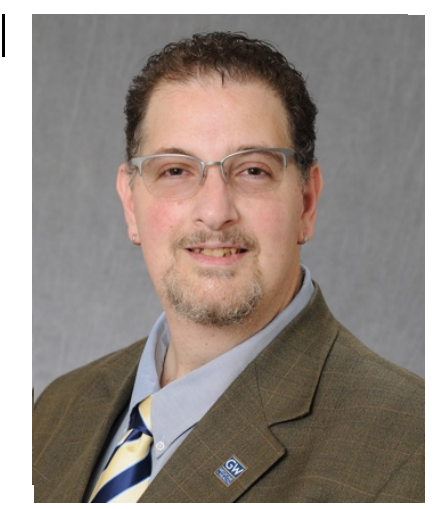

Gaetano R. Lotrecchiano, EdD, $\mathrm{PhD}$ is an associate professor at the George Washington University School of Medicine and Health Sciences, Washington, DC USA where he is the Director of Doctoral Candidacy in the PhD in Translational Health Sciences Program. He is the foundational Vice-President for the International Society for Systems and Complexity Science for Health and the International Network for the Science of Team Science. He is the convener of the GW program entitled Creating a Culture of Collaboration at GWU. He also the Team Science Lead for the Clinical and Translational Science Institute (CTSI-CN), a partnership between Children's National Health System and George Washington University.

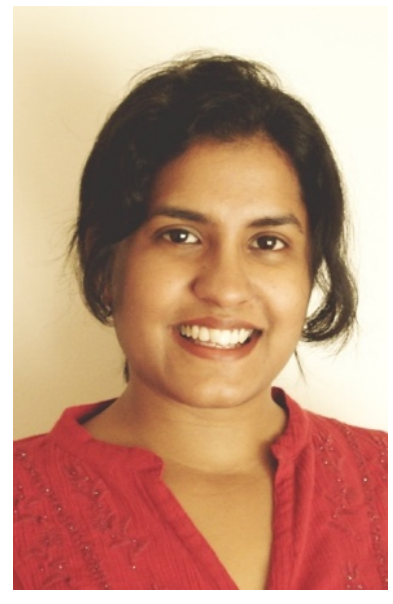

Shalini Misra, $\mathbf{P h D}$, is an Assistant Professor in the School of Public and International Affairs at Virginia Tech. Her research focuses on the social, psychological, and cultural implications of the Internet and mobile communication technologies; and the study of the processes and outcomes of transdisciplinary collaborative scientific, training, and action research initiatives. Key themes in her research and writing include: cognitive and health consequences of information overload and multitasking; interpersonal relationships in ubiquitous computing environments; environmental orientations, identity, and sense of community in the Digital Age; contextual influences on interdisciplinary collaboration; interdisciplinary education and curriculum development; and evaluation of team science initiatives. Her research has been supported by grants from NSF, $\mathrm{NIH}$, Urban Communication Foundation, Intel Digital Cultures, and the National Academies Keck Futures Initiative. She has a Ph.D. in Planning, Policy, and Design from University of California Irvine, an M.S. degree in Sustainable Resource Management (Technical University of Munich, Germany) and a B.S. degree in Civil Engineering (Gujarat University, India). 